\title{
Gender roles in social network sites from generation $\mathrm{Y}$
}

\author{
Francisco Javier Rondán-Cataluña ${ }^{1^{*}}$, Borja Sanz-Altamira ${ }^{1}$, Begoña Peral-Peral ${ }^{1}$
}

\begin{abstract}
One of the fundamental and most commonly used communication tools by the generation Y or Millennials are online social networks. The first objective of this study is to model the effects that exercise social participation, community integration and trust in community satisfaction, as an antecedent of routinization. Besides, we propose as a second objective checking if gender roles proposed to underlie the different behaviors that develop social network users. An empirical study was carried out on a sample of 1,448 undergraduate students that are SNS users from Generation Y. First, we applied a structural equation modeling approach to test the proposed model. Second, we followed a methodology using a scale of masculinity and femininity to categorize the sample obtaining three groups: feminine, masculine, and androgynous.
\end{abstract}

Keywords: sex roles; masculinity; femininity; androgyny; social networking sites (SNS); Generation Y.

Submitted: April 27 $2016 /$ Approved: October $5^{\text {th }} 2017$

\section{Introduction}

Internet users may use social networking sites (SNS) with various degrees of intensity. An SNS user can merely visit websites but can also contribute, disseminate, share and collaborate. Specifically, communication is a crucial part of keeping contact with our social ties. Social connections are an essential part of everyone's life. In this media-dominated world, all the people tend to go back to the very purest form of getting trusted information by asking friends for recommendations and advice. Recently, some authors presented a review of academic works on SNS indicating that gender role and age are still being exciting topics about SNS (Tsay-Vogel, 2015).

Among the users of social networks sites (SNS) highlight individuals belonging to Generation Y or Millennial Generation, born during the 1980s and early 2000s. Millennials are the first generation to grow up with the new technologies, having constant access to technology in their youth, and using it at higher rates than people from other crops, especially in comparison to the older age cohorts. There is no agreement on the archetypes that give Generation $\mathrm{Y}$ a specific character. In the other hand, other works questioned these predictions and attributed this generation with the traits of confidence and tolerance, but also with a sense of entitlement and narcissisms (Twenge, Campbell, \& Freeman, 2012).

Many studies have tried to find sex differences in Information and Communication Technology (ICT) and sex associations with SNS use in the case of Millennials. For instance, the influences of diverse issues on the continued use of information technology diverge due to biological gender differences (K. Y. Lin \& Lu, 2011) or the different behavior in online purchasing, being significantly higher for men the level of purchases than for women. Other studies found significant differences between traditional genders in Facebook use or gender impact. Concretely men are more persuasive than women and women influence men more than they affect other women (Aral \& Walker, 2012).
Furthermore, some authors (Baruh, Chisik, Bisson, \& Şenova, 2014) have revealed a predisposition for male profile viewers to reply more positively to information published by profiles from other males. For female viewers, this result was less important.

According to Valerio, there are slight sex differences focused on the management of photographs and variety of contents in the use of SNS among college students, maybe because it is a reproduction of the traditional stereotype that for women, their image is more important than for men (Valerio, 2014). Colas et al. (2013) showed that women are more implicated with SNS than males. Besides, young men use SNS to cover emotive features and strengthen their self-esteem, while for women of the same age, the interpersonal purpose predominates (Colás, González, \& de Pablos, 2013).

However, the current generation of students in higher educational settings is seeking a more radical change in gender roles beyond the binary of male/female, in particular when using networking sites. In this sense, Bem some decades ago proposed that masculinity and femininity occur on two distinct continuums rather than the typical male-female question. Later, Hofstede suggests there are nations with "masculine cultures" or "feminine cultures" people, and Yoo et al. adapt Hofstede's cultural dimensions scale to assess masculinity/ femininity at the individual level. As Srite and Karahanna noted, masculinity and femininity are not synonymous with gender defined by biological sex. They measure a psychological aspect of sex; therefore, men and women can possess masculine and feminine values to different extents (Srite \& Karahanna, 2006).

Consequently, it seems interesting to wonder if gender roles have changed over time with regards to new technologies, such as social network sites (SNS) in Generation Y. For this, the objective of this paper is to develop a model to demonstrate the factors that lead to satisfaction and routinization of SNS in Generation Y and to analyze the influence of gender roles in this model. Therefore, this study

(1) Dpt. Administración de Empresas y marketing, University of Seville, Spain.

${ }^{\star}$ Corresponding author: rondan@us.es 
examines whether the evolution of gender roles shows differences in their behavior concerning the model. Hence, an empirical research was carried out on a sample of 1,448 undergraduate students from a Spanish University that are SNS users from Generation Y. First, we reviewed the literature concerning the concepts SNS and the masculinity and femininity. After presenting the model and the hypothesis, we applied a structural equation modeling approach, using Partial Least Square methodology, to test the model that proposes that community integration, social participation, and trust shown by individuals when using SNS, are positively related to their satisfaction. And the latter will influence the routinization, defined as assimilating the technology into daily habits in Generation Y. Secondly, we followed Bem's methodology using Hofstede's scale of femininity and masculinity to categorize the sample and test if there are differences between these groups in the model.

\section{Proposed model}

Researchers have observed SNS by a diversity of procedures and theoretical foundations from various disciplines. In this paper, community satisfaction refers to the emotional reply to the usage of the applications and facilities delivered by the SNS. Some studies have shown satisfaction as an antecedent of loyalty and subjective wellbeing (Chiu, Cheng, Huang, \& Chen, 2013). Based on expectancy disconfirmation theory (EDT) (OLIVER, 1980)1980 and the information systems (IS) success model (Delone \& McLean, 2003), satisfaction has been considered a significant element of continuance intention in research about new technologies. Besides, the constant use of SNS is likely to become progressively automatic. Therefore, SNS users may repeat a sequence of well-learned activities without being aware of it (Kang, Min, Kim, \& Lee, 2013). Routinization is connected to "habitual usage - that is, to integrate the technology into daily routines" (Schwarz \& Chin, 2007), p. 240). As followers practice an SNS habitually, they turn into more habituated to it, decreasing ambiguity in future decisions. Routinization does not necessarily denote that someone uses the maximum degree of possibility accessible from the SNS, but its usage turns into individual's daily routine (SanchezFranco \& Roldan, 2010). According to these ideas hypothesis 1 is formulated:

\section{$H_{1}$ : Community satisfaction is positively related to routinization.}

Other studies have demonstrated the relationship between satisfaction and sense of belonging or community integration ( $\mathrm{H}$. Lin et al., 2014). Community integration can be specified as "members' feelings of membership, identity, belongingness, and attachment to a group that interacts primarily through electronic communication" (Blanchard, 2007), p. 827). Followers generate their identities within the SNS. Therefore, community integration will be a sense of recognizing with the SNS that affiliates also share with one another (SanchezFranco \& Roldan, 2010).

In this paper, we conceptualize social participation as community involvement, social interaction, or active involvement in community activities. This concept highlights the social community's interactivity level, raising the chances for support interchange. Social participation is consequently related to the position to which people are dynamic followers of the SNS and implicated in social activities in the SNS, emphasizing the utility of such contacts to the requirements of the community organization. Consequently, social participation pursues to apprehend the degree to which people actively offer support and get involved in community actions. Social participation will, therefore, be essential for lasting sustainability and, thus, a crucial driver of prosperous SNS (Sanchez-Franco \& Roldan, 2010). According to the thoughts mentioned above hypothesis 2 and hypothesis 3 are verbalized:

$\mathrm{H}_{2}$ : Social participation is positively related to community satisfaction.

$H_{3}$ : Community integration is positively related to community satisfaction.

Satisfaction connects to the positive emotional reactions of followers who discover mutual interactions rewarding. Adherents who trust on an SNS will be loyal to it, and consequently, they will be satisfied with it. Above all, trust is described by the feelings of safety and perceived the power of the association and is entirely more narrowed to individual experiences with the principal partner (Johnson \& Grayson, 2005). Therefore, we assume trust as the integration of two concepts: exchange partner's integrity and benevolence. Following the previous thinking, we formulate hypothesis 4 :

$H_{4}$ : Trust is positively related to community satisfaction.

Figure 1. presents the proposed model summarizing all the hypotheses.

Figure 1. Proposed model

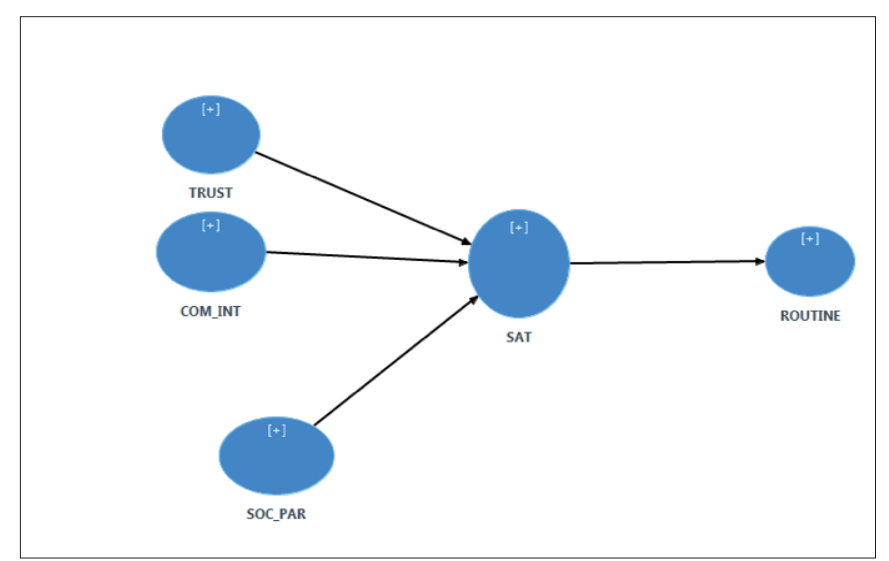

\section{Masculinity/Femininity}

Hofstede proposes analyzing the Nations around the world in function of a series of features, one of them difference masculinity and femininity (G. H. Hofstede, 2001)2001. Higher scores indicate high masculine societies. In this type of communities or "masculine cultures" people (men and women) tend to value assertiveness, ambition, competitiveness, and the accumulation of wealth and material possessions. However, people (again men and women) tend to value other variables such as relationships and quality of life in "feminine cultures." Besides, usually, the differences between gender roles are 
more dramatic and less fluid in masculine cultures than in feminine cultures (Cumming, Fleming, Johan, \& Takeuchi, 2010). The Masculinity scale is the most controversial of Hofstede's dimensions. As time went on, Hofstede has changed the definition of Masculinity/ Femininity to emphasize women's equality in the workplace. Nowadays, Hofstede defines the masculinity versus femininity dimension as: "The masculinity side of this dimension represents a preference in society for achievement, heroism, assertiveness and material reward for success. Society at large is the most competitive. Its opposite, femininity, stands for a preference for cooperation, modesty, caring for the weak and quality of life. Society at large is more consensus-oriented" (G. Hofstede).

Nevertheless, for firms and organizations, the reflection of the culture at the individual level is more important and relevant. Managers know that treating as equivalent the stereotypical culture of a country with all people of the country is a grave mistake, especially in those countries having the heterogeneous population with different cultural backgrounds (Yoo, Donthu, \& Lenartowicz, 2011).

Many research contexts have widely used Hofstede's metric at both country and individual levels in cross-cultural studies. Some authors have used it at the personal level, such as in consumer ideologies (Swaidan, Rawwas, \& Vitell, 2008), and in consumer ethnocentrism (Cleveland, Laroche, \& Papadopoulos, 2009). Yoo et al. developed a scale to assess Hofstede's cultural dimensions at the individual level named CVSCALE (Individual Cultural Values Scale) (Yoo et al., 2011). Their study divides the measurement of this aspect into two separate parts: masculinity and femininity.

At the individual level, Bem (1974) suggested that gender is a conduct: men might show certain stages of behaviors that might have been conventionally observed as being feminine, and women might also reveal specific actions that would have conventionally been considered as masculine. Besides, she proposed the term "androgynous" for those who have both male and female attributes. The aim of her work was different from Hofstede's intention, but the psychological backgrounds of their measures were similar.

Some studies analyses the use of ICTs and sex roles identified by Bem (1974). Bozionelos found that individuals who score higher on expressiveness (femininity in Bem's terminology) are more likely to report interest in learning about and utilizing computers (Bozionelos, 2002). Other authors (Venkatesh, Morris, Sykes, \& Ackerman, 2004) pointed out that attitude influences masculine individuals, while subjective norms and perceived behavioral control were significant in the case of female ones. Regarding androgynous, the three variables were significant. And Tufekci agrees that, regarding masculinity vs. femininity, information technology (IT) adoption and usage can differ (Tufekci, 2008).

Other studies analyzed cultural issues of website documents and their relation to masculinity-femininity dimension, suggesting the use of the concept of androgyny to develop more effective communications on the Web (Zahedi, Van Pelt, \& Srite, 2006). In fact, females try to report an androgynous profile in SNS, because for their psychological comfort, they evaluate positively to have both feminine and masculine characters (Renau Ruiz, Carbonell, \& Oberst, 2012).

Meanwhile, Hupfer and Detlor consider gender-related self-concept traits known as self- and other-orientation (Hupfer \& Detlor, 2007). Other-orientation presents common characteristics- nurturing, understanding, compassionate, sympathetic and sensitive- and was a positive predictor of using the Internet to find friends or relationships and of how often respondents reported using internet applications. Furthermore, other-orientation is related to a more effortful search strategy and higher search frequency. These studies conclude that 50 percent of women and 25 percent of men show other-oriented behavior (Hupfer \& Detlor, 2007).

Androgynous individuals might display sex role adaptability across situations, acting without worrying about the most appropriate stereotype for one sex or the other (Bem \& Lewis, 1975). In this respect, the Internet and its applications can affect the behavior of individuals since conceptualizations of masculinity might be different in online and offline environments. Computers create an impersonal social situation in which individuals feel more anonymous and can behave freely regardless of what others might think.

Only a few studies have attempted to differentiate among SNS users according to their personality characteristics. Concerning SNSs, one of the primary motivations to use them is seeking social support, and this motivation can be closer socially to the sensitive nature of feminine cultures rather than to more masculine ones because feminine role endorses more common and socio-emotional traits. However, other authors found that masculinity was positively correlated with time spent on Facebook but not on LinkedIn (Shneor \& Efrat, 2014). The engagement may serve as a platform for exhibiting social power and prestige if the number of friends in an SNS is an indicator of social status. Lewis and George tested theoretical explanations about the role of culture (including the masculinity dimension) in deception in SNS (Lewis \& George, 2008). It is likely that this cultural magnitude measured at the individual level can be discriminant in the segmentation of SNS users.

According to the ideas mentioned above the next proposition is formulated.

Proposition. People from Generation $Y$ have different behavior about the proposed model according to gender roles in the context of SNS.

\section{Methodology}

The literature suggests that the more someone is involved and familiar with Web 2.0 interactive tools and applications, as SNS, the more he or she will trust and will be satisfied with the virtual medium. Therefore, an empirical study was carried out on a sample of 1,448 undergraduate students, included in Generation Y. The statistical analysis involved two stages.

Firstly, we applied a structural equation modeling (SEM) approach to test the proposed model, using SmartPLS 3.0. First, the model 
was validated and tested. Then, based on masculinity and feminity Hofstede's scale, we use Bem's methodology. This methodology is the best to characterize the nature of the person's gender role: calculating the difference between an individual's masculinity and femininity normalized concerning the standard deviations of his or her masculinity and femininity scores (Bem, 1974), p. 158). This procedure allows us to propose three groups: masculine, feminine y androgynous. Finally, the Henseler's Multigroup Analysis was carried out using as groups the three gender roles obtained.

\section{Sample}

Empirical research using a non-probabilistic sampling method validated the theoretical model and the hypotheses discussed above. We collected surveys from February to March 2012. The sample size is 1,460 undergraduate students that are SNS users from Generation Y, from a public university located in the south of Spain. All of them were studying in different courses of business, marketing, economics or tourism management degrees.

Once we collected the questionnaires, those answered by students over 30 were eliminated from the sample, because the object of study was students belonging to Generation Y, resulting in 1,448 valid surveys. Demographic information of this selection of students is as follows. The average age of the sample is 20 years old, $57.6 \%$ are females, $95.1 \%$ singles, the average size of their households is 3.63 individuals, and $92.4 \%$ had three years of experience as Internet users. As for the SNS, 85\% were users for two years. Home is the principal place chosen for connecting to the network ( $94.5 \%$ of cases), followed by the study center $(26.3 \%)$. The laptop is the device most commonly used to connect to the network (87\%), followed by mobile phone $(47.5 \%)$. Regarding the frequency and time of access, $84.3 \%$ accessed at least once a day and half of the respondents spent more than an hour of their time to connect to the network. The average number of contacts was 300 . It is noticeable that $74.2 \%$ of respondents use mainly Tuenti as SNS, a Spanish SNS created in 2006, and it has more than 14 millions of users. Facebook is the second SNS more preferred by the respondents.

All these demographic and uses of SNS features were analyzed to determine if there were differences due to the sex of the respondent. In all cases, there were no statistically significant differences between men and women.

\section{Measures}

Confirmed items adapted from preceding revisions were used to measure routinized behavior, social satisfaction, trust, community integration, social participation and masculinity/femininity. Also, selected scales were adapted to make them applicable to the SNS-based environment. We measured routinized behavior using the three items from Sanchez-Franco and Roldan (Sanchez-Franco \& Roldan, 2010). The social satisfaction measure was adapted from Flavian et al. (Flavián, Guinalíu, \& Gurrea, 2006). The trust scale was adjusted from McKnight et al. (McKnight, Choudhury, \& Kacmar, 2002). Sca- les taken from Casaló et al. (Casaló, Flavián, \& Guinalíu, 2007) and Sanchez-Franco and Roldan (Sanchez-Franco \& Roldan, 2010) were adapted to measure community integration and social participation. Finally, the masculinity/ femininity scale has been measured through two constructs adjusting the scales of some previous studies (G. H. Hofstede, 2001)2001; (Srite \& Karahanna, 2006); (Yoo et al., 2011). All items are seven-point Likert-type, ranging from «strongly disagree», 1 , to «strongly agree», 7 .

A trial test of the questionnaire was conducted to assess the content validity and to clarify ambiguous and non-discriminating items, without additional suggestions.

\section{Statistical tool}

The first part of the methodology was to use SmartPLS 3.0 software to validate and estimate the proposed model. The use of PLS rather than other kinds of SEM technics is also applicable at this point because (Diamantopoulos \& Winklhofer, 2001): this work is exploratory; and SmartPLS is a nonparametric technique, so scholars do not need to guarantee the normality of the data. Further, this method is becoming more significant, ought to the number of articles using it in the leading journals (Henseler, Ringle, \& Sinkovics, 2009).

Then we applied Bem's procedure to calculate the Androgyny Score (AS). This process consists of deducting individual's masculinity and femininity normalized concerning the standard deviations of his or her masculinity and femininity scores. The Androgyny Score reveals the relative quantities of masculinity and femininity that somebody embraces in his or her self-description, and, as such, it best typifies the type of the person's total sex role. The higher the value of AS, the higher the predisposition of the person to femininity (high positive scores) or masculinity (high negatives scores). On the contrary, the closer the AS is to zero, the more the individual is androgynous (Bem, 1974). After this, we performed a multigroup analysis between people tending to masculinity, to femininity, and to androgyny. Multigroup variable has a moderating effect whereby a categorical moderator variable states each subject's group membership (Henseler et al., 2009).

\section{Results}

Routine construct achieves an R square of 0.264 and $\mathrm{R}$ square of the Satisfaction construct is 0.508 . Table 1 presents composite reliability, Cronbach's Alpha, and AVE.

Table 1. AVE, composite reliability, and Cronbach's Alpha.

\begin{tabular}{|l|c|c|c|}
\hline & AVE & $\begin{array}{c}\text { Composite } \\
\text { Reliability }\end{array}$ & $\begin{array}{c}\text { Cronbach's } \\
\text { Alpha }\end{array}$ \\
\hline TRUST & 0.623 & 0.929 & 0.912 \\
\hline COM_INT & 0.551 & 0.895 & 0.865 \\
\hline SOC_PAR & 0.606 & 0.859 & 0.782 \\
\hline SAT & 0.801 & 0.924 & 0.876 \\
\hline ROUTINE & 0.831 & 0.936 & 0.898 \\
\hline
\end{tabular}


Table 2. Discriminant validity (Fornell-Larcker criterion)

\begin{tabular}{|l|c|c|c|c|c|}
\hline & TRUST & COM_INT & SOC_PAR & SAT & ROUTINE \\
\hline TRUST & 0.789 & & & & \\
\hline COM_INT & 0.522 & 0.742 & & & \\
\hline SOC_PAR & 0.397 & 0.641 & 0.778 & & \\
\hline SAT & 0.442 & 0.695 & 0.549 & 0.895 & \\
\hline ROUTINE & 0.248 & 0.547 & 0.569 & 0.514 & 0.911 \\
\hline
\end{tabular}

As can be seen from Table 1, each average variance extracted (AVE) value is above 0.50 , which points out the good convergent validity of the scale. Every amount of composite reliability and AVEs are considered satisfactory. The diagonal elements (square root of AVEs) are higher than the correlation of that construct with all the other constructs in the model (see Table 2), which indicates satisfactory discriminant validity (Fornell \& Larcker, 1981). We further tested for potential multicollinearity, all inner and outer scores of VIF collinearity statistics are below 5 , this indicates that there are not multicollinearity problems in the data (O'brien, 2007). Standardized root mean square residual (SRMR)_was 0.046, as it was less than 0.08, the model shows an appropriate goodness-of-fit.
Next, we present the structural model of SmartPLS results. Path coefficients were calculated using a bootstrapping with 5,000 samples. All path coefficients are statistically significant (all $p$ values are 0 ) and positive (Table 3). The most robust relationships are between community integration and satisfaction, and between satisfaction and routine (supporting hypotheses $\mathrm{H} 3$ and $\mathrm{H} 1$, respectively). The other connections are also positive and significant, social participation and trust are positively related to community satisfaction (supporting hypotheses $\mathrm{H} 2$ and $\mathrm{H} 4$, respectively). As a consequence, the study confirms all the hypotheses.

Table 3. Path coefficients.

\begin{tabular}{|l|c|c|c|}
\hline & Path coefficient & T Statistics & P Values \\
\hline TRUST -> SAT & 0.094 & 4.062 & 0.000 \\
\hline COM_INT-> SAT & 0.540 & 19.935 & 0.000 \\
\hline SOC_PAR -> SAT & 0.165 & 6.511 & 0.000 \\
\hline SAT - > ROUTINE & 0.510 & 23.603 & 0.000 \\
\hline
\end{tabular}

Figure 2 represents the path coefficients for the whole sample.

Figure 2. Path coefficients of the model

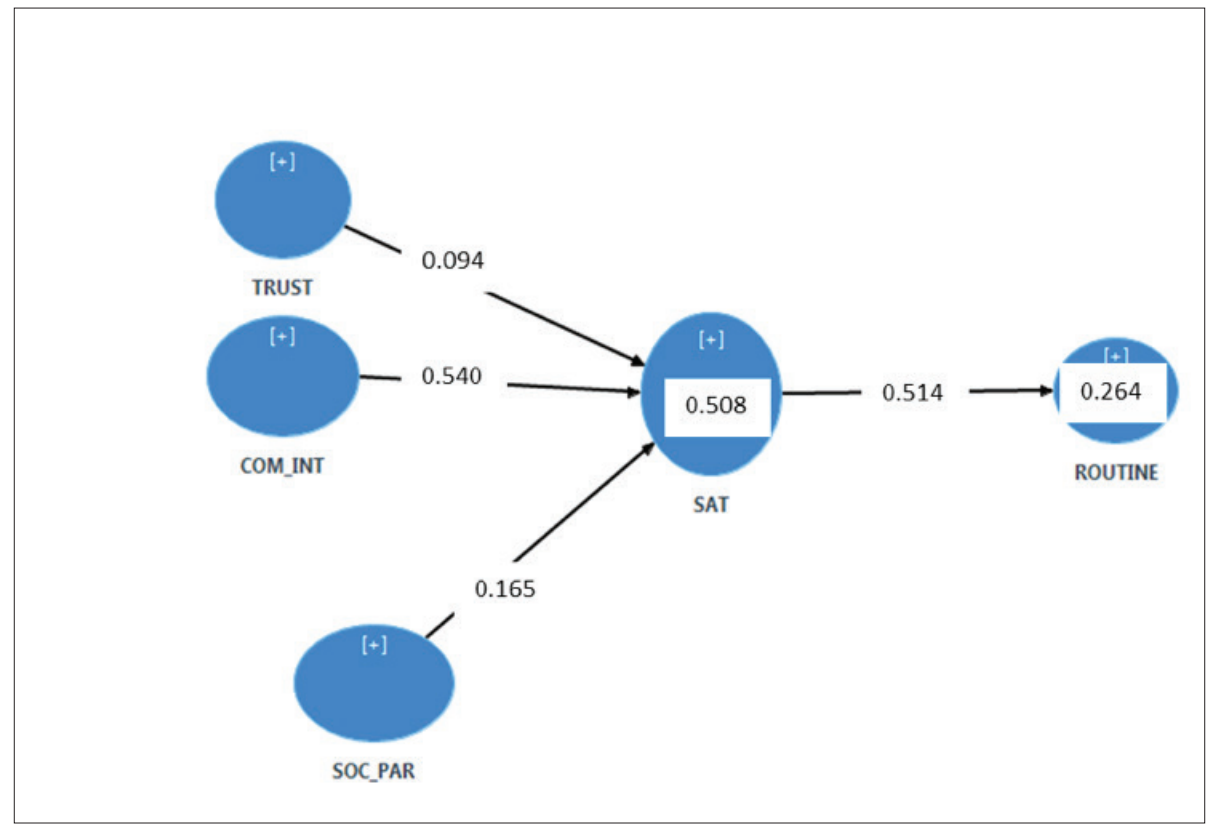

Table 4 presents the groups obtained regarding the gender roles.

Table 4. Classification of subjects according to gender roles.

\begin{tabular}{|c|c|c|c|}
\hline & Males $(\mathrm{n}=608)$ & Females $(\mathrm{n}=840)$ & Total $(n=1448)$ \\
\hline$\%$ feminine & $\begin{array}{c}3.2 \% \\
(\mathrm{n}=46)\end{array}$ & $\begin{array}{c}9.4 \% \\
(\mathrm{n}=136)\end{array}$ & $\begin{array}{c}12.6 \% \\
(1<\mathrm{AS}<1.83)^{*}\end{array}$ \\
\hline$\%$ androgynous & $\begin{array}{c}26.6 \% \\
(\mathrm{n}=385)\end{array}$ & $\begin{array}{c}33.1 \% \\
(\mathrm{n}=480)\end{array}$ & $\begin{array}{c}59.7 \% \\
(-1 \leq \mathrm{AS} \leq 1)^{*}\end{array}$ \\
\hline$\%$ masculine & $\begin{array}{c}12.2 \% \\
(\mathrm{n}=177)\end{array}$ & $\begin{array}{c}15.5 \% \\
(n=224)\end{array}$ & $\begin{array}{c}27.7 \% \\
(-1.87<\mathrm{AS}<-1)^{*}\end{array}$ \\
\hline
\end{tabular}

* Androgyny scores obtained in this research
The highest percentage of individuals in the sample corresponds to the androgynous, made up $63.3 \%$ of men and $57 \%$ of women, reflecting that the current generation of young behaves according to more flexible gender roles. These are individuals who are both male and female, both assertive and yielding depending on the situational appropriateness of behaviors. There are also students who appreciate behaviors inconsistent with those traditionally expected of his/her sex: $7.5 \%$ of men value the feminine aspects, and $26.2 \%$ of women (more than triple) appreciate the masculine characteristics. However, in the sample, we also found individuals who behave as sex-typed standards: $29.1 \%$ of men and $16.2 \%$ of women. 
Afterward, we present the results of the multi-group analysis. The previously tested model is applied to each group to search for differences in the relationships between students classified as androgy- nous and students classified oriented to masculinity and those geared to femininity and between the last two, performing three multi-group analyses.

Table 5. Path coefficients for groups androgynous vs. feminine and Henseler's MGA.

\begin{tabular}{|ccccc|}
\hline & $\begin{array}{c}\text { Path Coefficients } \\
\text { Original (androgynous) }\end{array}$ & $\begin{array}{c}\text { Path Coefficients } \\
\text { Original (femenine) }\end{array}$ & $\begin{array}{c}\text { Path Coefficients-diff } \\
\text { (androgynous - femenine |) }\end{array}$ & $\begin{array}{c}\text { p-Value (androgynous } \\
\text { vs. femenine) }\end{array}$ \\
$\begin{array}{c}\text { TRUST -> SAT } \\
\text { COM_INT -> } \\
\text { SAT }\end{array}$ & 0.095 & 0.038 & 0.058 & 0.197 \\
$\begin{array}{c}\text { SOC_PAR -> SAT } \\
\text { SAT -> ROUTINE }\end{array}$ & 0.491 & 0.582 & 0.091 & 0.887 \\
\hline
\end{tabular}

We can observe that path coefficients for feminine and androgynous groups are quite similar and p-values of Henseler's Multigroup Analysis are over 0.05 (Table 5). As a consequence, both teams of students have the same behavior about the model. Therefore, there is not a gap between people more oriented to femininity and those classified as androgynous, in students from Generation Y concerning the proposed model.

Table 6. Path coefficients for groups androgynous vs. masculine and Henseler's MGA.

\begin{tabular}{|c|c|c|c|c|}
\hline & $\begin{array}{c}\text { Path Coefficients } \\
\text { Original (androgynous) }\end{array}$ & $\begin{array}{c}\text { Path Coefficients } \\
\text { Original (masculine) }\end{array}$ & $\begin{array}{c}\text { Path Coefficients-diff } \\
\text { (androgynous - masculine|) }\end{array}$ & $\begin{array}{l}\text { p-Value (androgynous } \\
\text { vs. masculine) }\end{array}$ \\
\hline TRUST $->$ SAT & 0.095 & 0.123 & 0.028 & 0.717 \\
\hline SOC_PAR $->$ SAT & 0.193 & 0.090 & 0.103 & 0.032 \\
\hline SAT $->$ ROUTINE & 0.528 & 0.455 & 0.072 & 0.080 \\
\hline
\end{tabular}

In table 6 we can observe that two of the relationships are statistically different between androgynous and masculine. The positive connection between satisfaction and routine is stronger for androgynous than for people categorized as masculine (90\% of confi- dence level). The same fact occurs on the relationship between social participation and satisfaction (95\% of confidence level). The other two connections of the model do not change significantly in both groups.

Table 7. Path coefficients for groups feminine vs. masculine and Henseler's MGA.

\begin{tabular}{|c|c|c|c|c|}
\hline & $\begin{array}{l}\text { Path Coefficients } \\
\text { Original (femenine) }\end{array}$ & $\begin{array}{l}\text { Path Coefficients } \\
\text { Original (masculine) }\end{array}$ & $\begin{array}{c}\text { Path Coefficients-diff } \\
\text { (| femenine - masculine } \mid)\end{array}$ & $\begin{array}{l}\text { p-Value (femenine } \\
\text { vs. masculine) }\end{array}$ \\
\hline TRUST $->$ SAT & 0.038 & 0.123 & 0.085 & 0.888 \\
\hline COM_INT $->$ SAT & 0.582 & 0.608 & 0.026 & 0.631 \\
\hline SAT -> ROUTINE & 0.601 & 0.455 & 0.145 & 0.016 \\
\hline
\end{tabular}

In this case (table 7), people categorized as feminine show stronger relationship between social participation on satisfaction and the latter on routine than the group masculine (95\% confidence level). This outcome indicates that, concerning SNS and Generation Y, people tending to masculinity values give less importance to social participation as an antecedent of satisfaction, and to the latter as an antecedent of routinization. Therefore, we can accept the initial proposition: People from Generation Y have different behavior concerning the proposed model according to sex roles in the context of SNS. 


\section{Discussion and Conclusions}

This paper explores the antecedents of satisfaction and routinization of SNS in the context of Generation Y through a model. All the proposed hypotheses are confirmed, showing that this model allows us to improve the knowledge about satisfaction and routinization of SNS in Generation Y. Furthermore, the proposition of different behaviors about this model is partially confirmed.

Social connections are critical to human biology, and the impact of SNSs on these relationships has been significant. Generation $\mathrm{Y}$ is the digital generation, the vanguard that represents the future, and the first generation to grow up with SNS; therefore, authors should incorporate a complete understanding of SNSs usage: patterns of use and online communication.

The authors focused on Generation Y because this is the group that is entering a phase of the lifecycle as they form families and households and will likely lead our society in a few years. The use of these social networks will influence the forms of communication for these young people. Therefore it is essential to know and understand the effects that SNS have in their lives. As this generation is likely to come under the attention from the researchers and practitioners, they would benefit from greater understanding of the issues that concern this group.

While many authors have written on SNS usage patterns, little research has focused on specific gender roles of Generation Y, particularly online. This paper addresses this gap by focusing on this cohort and offering insights into Millennials use of SNS depending upon the gender roles: femininity, masculinity, and androgyny. An essential result of this study is the number of people classified as androgynous; almost $60 \%$ of the sample, reflecting that the current generation of young behaves according to more flexible gender roles. Twenge (1997) found similar results. She studied subjects of the same age (college students) at different moments. Her outcomes point out that women have increasingly informed masculine-stereotyped personality characters as features of themselves, and men have also endorsed more masculine personality traits. This author suggests that personality can be affected by cultural changes. Therefore, the values and expectations formed during childhood are influenced by cultural and economic environments, so it is likely that the daughters of working mothers valued masculine aspects. Another theory suggests that female university students who intend to pursue a career, begin to acquire in college personality traits they consider necessary for success in the professional field, which is a traditionally masculine trait (Eagly, 2013). Furthermore, our sample is composed of students enrolled in degrees where cultural concepts such as making money, success in life, ambition, improve your professional career are cornerstones for them, opposite to other students enrolled in more humanistic studies. We believe that the business-economic scope of the students of our sample could influence the fact of obtaining a high percentage of women presenting masculine personality traits and women with high androgyny scores.
This model reveals there are differences in some of the relationships of the model when considering the gender-roles. Specifically, androgynous have a similar behavior than the female group. The masculine segment has behavior more away from the rest. Thus, feminine and androgynous show a stronger relationship between social participation on satisfaction and the latter on routine than the masculine group. This consequence points out that, concerning SNS and Generation $\mathrm{Y}$, people tending to masculinity values give less significance to social participation as an antecedent of satisfaction, and to the latter as an antecedent of routinization.

One might think that the difference in the relationship between the variables of the model between androgynous, feminine and masculine are due to their characteristics as users. However, there are no significant differences in time as an Internet or SNS user, or concerning the frequency of access to the SNS, or the number of contacts, whether one is androgynous, feminine or masculine. We believe, therefore, that this depiction of gender is highly influential in explaining by itself the SNS behavior of young people in the proposed model. In this regard some authors (Venkatesh et al., 2004) suggest that the psychological conceptualization of gender is a more accurate predictor of ICT adoption and user behavior than sex, because it has a lasting impact throughout the technology adoption lifecycle, influencing the decisions of long-term use.

This study extracted the results from a significant sample, with more than 1,400 people; one limitation is the lack of diversity in the sample, which was composed only of millennial university students. The research should be extended to other groups of people with different cultural levels and to other countries to extrapolate our findings to them.

\section{References}

Aral, S., \& Walker, D. (2012). Identifying influential and susceptible members of social networks. Science, 337(6092), 337-341.

Baruh, L., Chisik, Y., Bisson, C., \& Şenova, B. (2014). When Sharing Less Means More: How Gender Moderates the Impact of Quantity of Information Shared in a Social Network Profile on Profile Viewers' Intentions About Socialization. Communication Research Reports, 31(3), 244-251.

Bem, S. L. (1974). The measurement of psychological androgyny. Journal of Consulting and Clinical Psychology, 42(2), 155-162.

Bem, S. L., \& Lewis, S. A. (1975). Sex role adaptability: One consequence of psychological androgyny. Journal of Personality and Social psychology, 31(4), 634.

Blanchard, A. L. (2007). Developing a sense of virtual community measure. CyberPsychology \& Behavior, 10(6), 827-830.

Bozionelos, N. (2002). Computer interest: A case for expressive traits. Personality and individual differences, 33(3), 427-444. 
Casaló, L., Flavián, C., \& Guinalíu, M. (2007). The impact of participation in virtual brand communities on consumer trust and loyalty: The case of free software. Online Information Review, 31(6), 775-792.

Chiu, C. M., Cheng, H. L., Huang, H. Y., \& Chen, C. F. (2013). Exploring individuals' subjective well-being and loyalty towards social network sites from the perspective of network externalities: The Facebook case. International Journal of Information Management, 33(3), 539-552. doi:10.1016/j.ijinfomgt.2013.01.007

Cleveland, M., Laroche, M., \& Papadopoulos, N. (2009). Cosmopolitanism, consumer ethnocentrism, and materialism: an eight-country study of antecedents and outcomes. Journal of International Marketing, 17(1), 116-146.

Colás, P., González, T., \& de Pablos, J. (2013). Young People and Social Networks: Motivations and Preferred Uses. Comunicar, 40, 15-23.

Cumming, D., Fleming, G., Johan, S., \& Takeuchi, M. (2010). Legal Protection, Corruption and Private Equity Returns in Asia. Journal of Business Ethics, 95(2), 173-193. doi:10.1007/s10551-011-0853-6

Delone, W. H., \& McLean, E. R. (2003). The DeLone and McLean Model of Information Systems Success: A Ten-Year Update. J. Manage. Inf. Syst., 19(4), 9-30.

Diamantopoulos, A., \& Winklhofer, H. M. (2001). Index construction with formative indicators: an alternative to Scale development. Journal of marketing research, 38(2), 269-277.

Eagly, A. H. (2013). Sex differences in social behavior: A social-role interpretation: Psychology Press.

Flavián, C., Guinalíu, M., \& Gurrea, R. (2006). The influence of familiarity and usability on loyalty to online journalistic services: The role of user experience. Journal of Retailing and Consumer Services, 13(5), 363-375.

Fornell, C., \& Larcker, D. F. (1981). Evaluating Structural Equation Models with Unobservable Variables and Measurement Error. 18(1), 39-50.

Henseler, J., Ringle, C. M., \& Sinkovics, R. R. (2009). The use of partial least squares path modeling in international marketing. Advances in International Marketing, 20, 277-319.

Hofstede, G. NATIONAL CULTURE DIMENSIONS.

Hofstede, G. H. (2001). Culture's consequences: Comparing values, behaviors, institutions and organizations across nations: Sage.

Hupfer, M. E., \& Detlor, B. (2007). Beyond gender differences: Selfconcept orientation and relationship-building applications on the Internet. Journal of Business Research, 60(6), 613-619.

Johnson, D., \& Grayson, K. (2005). Cognitive and affective trust in service relationships. Journal of Business Research, 58(4), 500-507.
Kang, Y. S., Min, J., Kim, J., \& Lee, H. (2013). Roles of alternative and self-oriented perspectives in the context of the continued use of social network sites. International Journal of Information Management, 33(3), 496-511. doi:10.1016/j.ijinfomgt.2012.12.004

Lewis, C. C., \& George, J. F. (2008). Cross-cultural deception in social networking sites and face-to-face communication. Computers in $\mathrm{Hu}$ man Behavior, 24(6), 2945-2964.

Lin, K. Y., \& Lu, H. P. (2011). Why people use social networking sites: An empirical study integrating network externalities and motivation theory. Computers in Human Behavior, 27(3), 1152-1161. doi:10.1016/j.chb.2010.12.009

McKnight, D. H., Choudhury, V., \& Kacmar, C. (2002). Developing and validating trust measures for e-commerce: an integrative typology. Information systems research, 13(3), 334-359.

OLIVER, R. L. (1980). A Cognitive Model of the Antecedents and Consequences of Satisfaction Decisions. Journal of Marketing Research, 17(4).

O'brien, R. (2007). A Caution Regarding Rules of Thumb for Variance Inflation Factors. Quality \& Quantity, 41(5), 673-690. doi:10.1007/ s11135-006-9018-6

Renau Ruiz, V., Carbonell, X., \& Oberst, U. (2012). Redes sociales online, género y construcción del self. Aloma: Revista de Psicologia, Ciències de l'Educació i de l'Esport, 30(2).

Sanchez-Franco, M. J., \& Roldan, J. L. (2010). Expressive aesthetics to ease perceived community support: Exploring personal innovativeness and routinized behavior as moderators in Tuenti. Computers in Human Behavior, 26(6), 1445-1457. doi:10.1016/j. chb.2010.04.023

Schwarz, A., \& Chin, W. (2007). Looking forward: toward an understanding of the nature and definition of IT acceptance. Journal of the Association for Information Systems, 8(4), 13.

Shneor, R., \& Efrat, K. (2014). Analyzing the impact of culture on average time spent on social networking sites. Journal of Promotion Management, 20(4), 413-435.

Srite, M., \& Karahanna, E. (2006). The role of espoused national cultural values in technology acceptance. MIS Quarterly, 679-704.

Swaidan, Z., Rawwas, M. Y. A., \& Vitell, S. J. (2008). Culture and moral ideologies of African Americans. The Journal of Marketing Theory and Practice, 16(2), 127-137.

Tsay-Vogel, M. (2015). Me versus them: Third-person effects among Facebook users. New Media \& Society, 1461444815573476.

Tufekci, Z. (2008). Grooming, gossip, Facebook, and MySpace: What can we learn about these sites from those who won't assimilate? Information, Communication \& Society, 11(4), 544-564. 
Twenge, J. M., Campbell, W. K., \& Freeman, E. C. (2012). Generational differences in young adults' life goals, concern for others, and civic orientation, 1966-2009. Journal of personality and social psychology, 102(5), 1045.

Valerio, L. M. (2014). Facebook y los jóvenes universitarios: qué comunican según el género. Historia y Comunicación Social, 18, 77-87.

Venkatesh, V., Morris, M. G., Sykes, T. A., \& Ackerman, P. L. (2004). Individual reactions to new technologies in the workplace: the role of gender as a psychological construct. Journal of Applied Social Psycho$\log y, 34(3), 445-467$.
Yoo, B., Donthu, N., \& Lenartowicz, T. (2011). Measuring Hofstede's Five Dimensions of Cultural Values at the Individual Level: Development and Validation of CVSCALE. Journal of International Consumer Marketing, 23(3-4), 193-210. doi:10.1080/08961530.2011.578059

Zahedi, F. M., Van Pelt, W. V., \& Srite, M. (2006). Web documents' cultural masculinity and femininity. Journal of Management Information Systems, 23(1), 87-128. 